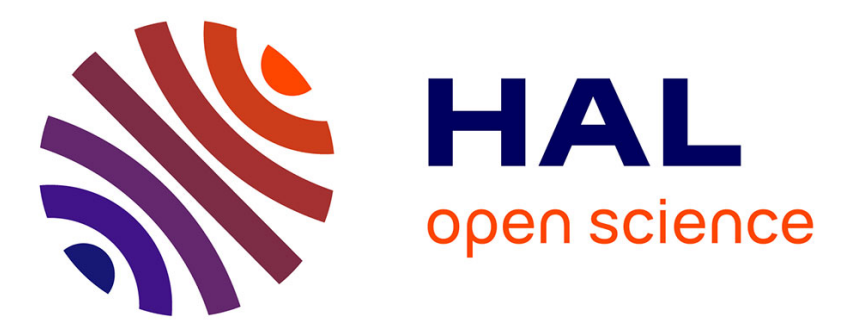

\title{
Evolution towards fossoriality and morphological convergence in the skull of Spalacidae and Bathyergidae (Rodentia)
}

Morgane Fournier, Lionel Hautier, Helder Gomes Rodrigues

\section{- To cite this version:}

Morgane Fournier, Lionel Hautier, Helder Gomes Rodrigues. Evolution towards fossoriality and morphological convergence in the skull of Spalacidae and Bathyergidae (Rodentia). Journal of Mammalian Evolution, In press, 10.1007/s10914-021-09550-z . hal-03244141

HAL Id: hal-03244141

https: / hal.sorbonne-universite.fr/hal-03244141

Submitted on 1 Jun 2021

HAL is a multi-disciplinary open access archive for the deposit and dissemination of scientific research documents, whether they are published or not. The documents may come from teaching and research institutions in France or abroad, or from public or private research centers.
L'archive ouverte pluridisciplinaire HAL, est destinée au dépôt et à la diffusion de documents scientifiques de niveau recherche, publiés ou non, émanant des établissements d'enseignement et de recherche français ou étrangers, des laboratoires publics ou privés. 
Evolution towards fossoriality and morphological convergence in the skull of Spalacidae and Bathyergidae (Rodentia)

Morgane FOURNIER ${ }^{1}$, Lionel HAUTIER ${ }^{2}$, Helder GOMES RODRIGUES ${ }^{1}$

${ }^{1}$ Centre de Recherche en Paléontologie - Paris (CR2P), UMR CNRS 7207, CP38, Muséum national d'Histoire naturelle, Sorbonne Université, 8 rue Buffon, 75005 Paris, France

${ }^{2}$ Institut des Sciences de l'Evolution, cc64, Université de Montpellier, CNRS, IRD, EPHE, F34095 Montpellier, France

\section{Corresponding author:}

Helder Gomes Rodrigues

Email address: helder.gomes-rodrigues@mnhn.fr

Telephone: +33140793814 


\begin{abstract}
Rodents show a wide range of anatomical, physiological, and behavioral adaptations to life underground. Cranial and postcranial bone morphologies are deeply impacted by the modes of digging, which can involve either incisors or claws. However, the morphological variation of these elements still needs to be accurately quantified to assess the degree of specializations of the fossorial rodent families in regards to their respective evolution. Here, we focus on the morpho-functional characteristics of the masticatory apparatus in two families of subterranean rodents, the Spalacidae and Bathyergidae. We quantify the skull shape in five spalacid genera using geometric morphometric methods, as well as biomechanical estimates for adductor muscles, which are compared with data previously published on bathyergids. We show that the skull shape of spalacids has a greater disparity and lower biomechanical estimates than bathyergids, in which the fossorial activity, notably chisel-tooth digging, more significantly impacted the evolution of the skull. Among spalacids, Spalax shows the most extreme specializations to life underground and displays the highest number of morphological convergences with chisel-tooth digging bathyergids, especially regarding its cranial shape and high biomechanical estimate for the temporalis muscle. Fewer morphological convergences were observed between other spalacids and bathyergids. Different evolutionary histories can potentially explain discrepancies observed between the two families, the first bathyergid morphological adaptations to fossorial life being much older than those of spalacids.
\end{abstract}

Keywords: Skull shape, fossorial adaptations, life underground, rodents, geometric morphometrics 


\section{Introduction}

Fossorial habits are widespread among mammals, but it is especially the case in rodents, which include ten families displaying important specializations to fossorial life: Aplodontidae, Sciuridae, Bathyergidae, Ctenomyidae, Octodontidae, Echimyidae, Geomyidae, Spalacidae, Cricetidae, and Muridae (Agrawal 1967; Nevo 1999; Lacey et al. 2000; Begall et al. 2007). Some species, recognized as subterranean, live underground to forage for food, reproduce, and disperse (Nevo 1979). These rodents show a specialized digging lifestyle, which is reflected by a number of physiological (e.g., low basal metabolic rate) and anatomical convergences (e.g., eyes and pinnae reduced, massive masticatory muscles; Morlok 1983; Stein 2000; Burda 2006). Subterranean species convergently evolved different modes of digging, from "scratch digging" characterized by alternate flexing and extension of forearms bearing enlarged claws to "chiseltooth digging" involving the use of procumbent incisors to scrape the ground. Digging with incisors is also suggested to be combined with shoveling movements of the head in a few cases (Hildebrand 1985; Laville et al. 1989; Stein 2000). These different modes of digging are associated with important morphological variations of the body (e.g., head and limbs), which remain to be accurately described, to better understand the different adaptive events to burrowing life in rodents.

Two phylogenetically distant rodent families, the Spalacidae and Bathyergidae, display some of the most extreme specializations to fossorial life. Spalacids belong to the superfamily Muroidea and comprise at least six genera from Asia (bamboo rats: Cannomys and Rhizomys; zokors: Myospalax and Eospalax), Eurasia and northern Africa (blind mole rats: Spalax and Nannospalax), and eastern Africa (African root-rats: Tachyoryctes; Norris 2017). Bathyergids, or African mole-rats, belong to Ctenohystrica and comprise six genera (Bathyergus, Fukomys, Cryptomys, Georychus, Heliophobius, and Heterocephalus; Kock et al. 2006). The spalacid and bathyergid current diversity is the result of adaptive radiations dating back from the middle to 
late Miocene, while their origins probably took place during the Oligocene (Cook et al. 2000; Mein and Pickford 2008; Flynn 2009; de Bruijn et al. 2015; Steppan and Schenk 2017; He et al. 2020; Fig. 1). The two families show numerous physiological, anatomical, and behavioral convergences to life underground (e.g., Nevo 1979; Stein 2000; Sahm et al. 2018), including all recognized digging modes (Stein 2000; Fig. 1). For instance, the bathyergid Heterocephalus and the spalacid Spalax, representing the most studied genera in each family, evolved very similar adaptations to survive in hostile conditions, such as tolerance to hypoxia, extensive longevity (i.e., more than 20 years), and resistance to cancer (e.g., Sherman and Jarvis 2002; Kim et al. 2011, Manov et al. 2013; Fang et al. 2014; Kirby et al. 2018). The high number of convergences observed in Spalacidae and Bathyergidae represents a suitable case to study the morphological specializations related to their respective adaptation to fossorial life.

Here, our aim is first to evaluate the impact of modes of digging in Spalacidae throughout a $3 \mathrm{D}$ quantification of their skull morphology using geometric morphometric methods. These data will be then compared to those obtained for bathyergids in a previous study (Gomes Rodrigues et al. 2016). Such a comparison will enable us to unravel disparity patterns between these families, as well as to discuss morphological convergences. In addition, we will quantify the mechanical advantage for adductor muscles to consider some morpho-functional aspects in relation to masticatory efficiency. More generally, these different analyses will permit us to discuss and compare the evolutionary mechanisms (e.g., phylogenetic inertia, ecology) shaping the skull of spalacids and bathyergids in relation to their different degrees of adaptation to life underground.

\section{Material and Methods}

\section{Sample composition}

The spalacid database is mainly composed of specimens stored in the Muséum National 
d'Histoire Naturelle in Paris (MNHN) and complemented by a few scanned specimens from the Natural History Museum in London (NHM, or for specimens: British Museum of Natural History, BMNH). We analyzed 25 mandibles and 38 crania representing five spalacid genera (Table 1; Online resource 1). Despite recent studies suggesting the monophyly of both Spalax and Nannospalax (Hadid et al. 2012; Norris 2017), only the genus Spalax is mentioned in this study, following Musser and Carleton (2005), because of undefined "Spalax" specimens. All bathyergid data were taken prior to the commencement of this study (Gomes Rodrigues et al. 2016).

\section{Geometric morphometric methods}

Mandibular and cranial forms of spalacids were quantified using 22 and 62 anatomical landmarks, respectively (Fig. 2; Online resource 2). This landmark dataset was based on previous studies (Hautier et al. 2012; Gomes Rodrigues et al. 2016) and was adapted to our sample. Landmarks \#29, \#37, \#48, and \#55 were not used in the analyses, but some landmarks were added at the tip of both the upper and lower incisors (landmarks \#79, \#80, \#81, \#82, \#83, and \#84). Digital data of all specimens were mostly acquired using a Microscribe 3-D digitizer. The skulls of Spalax and Myospalax were scanned using a Nikon Metrology HMX ST 225 at the CT facility of the NHM (London, UK) with a cubic voxel of $47.74 \mu \mathrm{m}$ and $58.13 \mu \mathrm{m}$, respectively, in order to visualize virtual deformations within the Spalacidae dataset and for imaging. The scans of the bathyergids, Bathyergus and Heliophobius, used for imaging, were published in previous studies (Gomes Rodrigues et al. 2015, 2016). Landmarks were then digitized on these reconstructed meshes using the 'LANDMARK editor' (http://graphics.idav.ucdavis.edu/research/EvoMorph).

For the cranium, landmarks are mostly of type 1 (juxtaposition of tissues). Because the mandible of rodents is constituted of a unique dentary bone of relatively simple shape, most of 
the landmarks taken on the dentary were of type 2 (e.g., maxima of curvature - Fig. 1; Bookstein 1991). All configurations (sets of landmarks) were superimposed using the Procrustes method of generalized least squares superimposition (GLS scaled, translated, and rotated configurations so that the intralandmark distances were minimized) following the method used by Rohlf (1999) and Bookstein (1991). Shape variability of the cranium and mandible was analyzed by principal components analyses (PCA; Figs. 3 and 4). Analysis and visualization of patterns of shape variation were performed with the interactive software package MORPHOTOOLS (Lebrun et al. 2010). We calculated neighbor joining trees in order to propose an overall representation of the morphological distance between each spalacid specimen. We used the $n j$ function from the ape R package (Paradis and Schliep 2019) computed on a matrix of Euclidian distances, previously calculated on the first PCs representing $90 \%$ of the shape variance (Fig. 5). The same analyses were performed separately with previously published data on bathyergids (Gomes Rodrigues et al. 2016).

Disparity analyses were conducted on cranial and mandibular datasets combining coordinates of both spalacids and bathyergids (excluding incisor landmarks missing in bathyergids). We used the geomorph version 3.2.1 function morphol.disparity, which used the Procrustes variation of both sets of landmarks (mandible and cranium) to measure pairwise morphological variance (Adams et al. 2020). Whole cranium and mandible disparities were then calculated for each family.

\section{Biomechanical analyses}

The mechanical advantage of each adductor muscle (i.e., temporalis, superficial masseter, and deep masseter) was estimated using the ratio of the inlever (distance from the condyle or fulcrum to the point of muscle attachment) and the outlever (distance from the condyle to the bite point; Hiiemae 1971). This method is not used here as a predictor of the absolute incisor 
bite force (see Ginot et al. 2019), but allows for inter-generic comparisons of the relative efficiency of incisors for each masticatory muscle. Three adductor muscles have been considered for inlevers (Fig. 2f): the temporalis, which attaches on the coronoid process (landmarks \#64 and \#73), the superficial masseter, which attaches along the angular process (landmarks \#68 and \#77), and the deep masseter, which attaches on the masseteric crest (landmarks \#69 and \#78) (Cox and Jeffery 2011; Baverstock et al. 2013; Renaud et al. 2015; Gomes Rodrigues et al. 2016). The bite point at the tip of the incisor was generally not used, because of large intraspecific variation due to wear (see Casanovas-Vilar and Van Dam 2013). Measurements of biomechanical advantage in spalacids did not show different trends whether we used the tip of the incisor (landmark \#83) or the posterior part of the alveolar margin of incisor (landmark \#60, Online resource 3). Following Gomes Rodrigues et al. (2016) and for a relevant comparison with data previously acquired on bathyergids, the landmark \#60 was then used for estimating the outlever. Three estimates of biomechanical advantage (inlever/outlever) were thus considered for a given mandible: T/I (temporalis/incisor), SM/I (superficial masseter/incisor), and DM/I (deep masseter/incisor; Fig. 6). Differences in the inlever/outlever ratios between spalacids as well as with bathyergids were tested using post-hoc multiple mean comparison tests: the Fisher's Least Significant Difference test (LSD) and the Tukey's Honestly Significant Difference test (HSD), the latter being less sensitive but more conservative than the former (Online resource 4). Estimates of biomechanical advantages were previously rank transformed data because they did not meet the assumptions (i.e., normality, homoscedasticity of variances) required for such parametric tests (Conover and Iman 1981).

\section{Results}

\section{Comparison of skull shape among Spalacidae}

On the PCA performed on crania, the first component explains $53.21 \%$ of the variance, 
while the second component explains $10.95 \%$, and the third component explains $8.24 \%$ (Fig. 3). Myospalax and Spalax show negative values on the first axis, associated with an anterodorsally elongated but poorly elevated snout, widened zygomatic arches with reduced jugal bones, a widened frontal area, and an occipital area dorsoventrally and laterally enlarged. In positive values, Rhizomys, Cannomys, and Tachyoryctes display more enlarged and procumbent incisors, and an enlarged squamosal area. On PC2, Tachyoryctes has positive values and is characterized by a long and thin snout, and enlarged incisors. In negative values, Rhizomys shows a short premaxilla and enlarged zygomatic arches. On PC3, Myospalax has the most negative values, with enlarged parietal, frontal, and basicranial areas. Specimens of Rhizomys, Tachyoryctes, and especially Spalax range from negative to positive values. In positive values, specimens are characterized by enlarged zygomatic arches, procumbent incisors, and a reduced molar row.

For the PCA performed on the mandible (Fig. 4), the first, second, and third components explain $46.71 \%, 15.71 \%$, and $9.30 \%$ of the variance, respectively. On PC1, Rhizomys, Tachyoryctes, and Cannomys display negative values, while Myospalax and Spalax sit on the positive side. Regarding shape deformations, Spalax exhibit a mandible with procumbent incisors, a condyle posteriorly and medially projected, and a laterally projected angular process. For Rhizomys, Tachyoryctes, and Cannomys, the condyle and the angular process are in alignment with the mandibular body, while the mandibular ramus is enlarged and the coronoid more elevated and close to the condyle. On PC2, Rhizomys takes positive values, whereas Cannomys and notably Tachyoryctes have negative values. Spalax shows specimens ranging from the negative side to the positive side of the component. On the negative side of PC2, specimens have a much longer and less expanded angular process than the others. In addition, the condylar process is medially oriented compared to the angular process in specimens on positive values. On PC3, only Myospalax specimens set apart from other spalacids in showing 
more positives values. They notably shows shorter incisors and a more robust and elevated mandible than other taxa.

\section{Comparison of morphological distances and disparity between spalacids and bathyergids}

We observed a very close pattern of morphological clustering between the crania and mandibles in spalacids according to the neighbor joining analyses, while it is not the case in bathyergids (Fig. 5). Moreover, the intra-generic (or intra-specific, cf. Fukomys) cranial distances are higher than for mandibular shapes, as some specimens are not clustered (e.g., for Tachyoryctes, Georychus, Fukomys), and this is true both for spalacids and bathyergids. In spalacids, Cannomys is morphologically closer to Tachyoryctes than to Rhizomys, and these taxa clearly set apart from Myospalax, and even more from Spalax. These differences are less marked when considering mandibular shape. In bathyergids, Bathyergus and Heterocephalus set apart from other taxa concerning crania, while the two species of Fukomys, Heliophobius, and Georychus are less morphologically distant. Mandibles of Bathyergus clearly depart from those of other bathyergids. Disparity results show that the spalacid mandibles and crania (Procrustes variances: 0.030 and 0.069 , respectively) are significantly more disparate $(\mathrm{p}<0.001)$ than those of bathyergids ( 0.014 and 0.034 , respectively).

\section{Comparison of biomechanical advantages between spalacids and bathyergids}

Spalacids tend to have lower lever arm ratio values than bathyergids, especially regarding the temporalis and deep masseter (Fig. 6). According to post-hoc tests (Online resource 4), Rhizomys, Cannomys, and Tachyoryctes do not show any significant difference, whereas Spalax significantly differ from other spalacids for the lever arm ratio of most muscles. More precisely, Spalax shows a high value for the lever arm ratio of the temporal muscle, like most bathyergids. Other spalacids, especially Tachyoryctes, have very low values for this ratio, 
which are always significantly lower than those of most bathyergids. In contrast, Tachyoryctes displays a high value for the lever arm ratio of the superficial masseter muscle, slightly lower than Bathyergus, but significantly higher than other bathyergids and spalacids. Spalax and Myospalax show the lowest values for this lever arm ratio. Spalacids, especially Spalax, show the lowest values of the lever arm ratio of the deep masseter muscle. Only Myospalax shows a value close to that of bathyergids.

\section{Discussion}

\section{Morphological disparity in spalacids and phylogenetic imprint}

Spalacids show a well-defined pattern of morphological differentiation, which is similar between the cranium and the mandible according to PCA and neighbor joining analyses. This pattern relies on the clustering of rhizomyines (Tachyoryctes, Rhizomys, and Cannomys), which clearly depart from Myospalax and Spalax. Such a pattern of morphological differentiation is in accordance with phylogenetic hypotheses, especially the monophyly of rhizomyines based on morphological and molecular data (e.g., Jansa and Weksler 2004; López-Antoñanzas et al. 2013; Steppan and Schenck 2017). However, the morphology of Cannomys is more different than that of Rhizomys, while both Cannomys and Tachyoryctes display similar morphological traits such as more procumbent upper and lower incisors (Stein 2000). This result should however be taken with caution as only one specimen of Cannomys could be considered in our analyses.

Myospalax and Spalax display similar morphological traits, such as non-procumbent upper incisors coupled to a poorly elevated snout, and a highly elevated posterior part of the cranium due to the enlargement of the occipital area (Fig. 7a and 7b). Jansa et al. (2009) proposed a close relationship between Spalax and Myospalax, but this assumption is weakly supported in their phylogenetic analysis. However, a more recent study (He et al. 2020) also 
suggested that spalacines and myospalacines are sister taxa. These shared morphological traits might be plesiomorphic, but might have been independently acquired during the evolution of these two lineages.

The position of myospalacines or spalacines as sister taxa of rhizomyines has also been debated. In our analyses, Myospalax is morphologically closer to rhizomyines than Spalax, which is also supported by our biomechanical estimates. This result corroborates previous phylogenetic assumptions based on paleontological and morphological data (Flynn 2009), or genomic approaches (Lin et al. 2014), but contradicts recent molecular studies suggesting that spalacines are sister clade to rhizomyines (e.g., Steppan and Schenck 2017). Discrepancies between the different phylogenetic studies (e.g., Lin et al. 2014; Steppan and Schenck 2017; He et al. 2020) could be explained by relatively close ages of divergence (i.e., between 25 and $22 \mathrm{Ma}$ ) between spalacines, myospalacines, and rhizomyines.

The putatively high phylogenetic component in the skull morphology of spalacids, which could not tested here because of low samples, is also corroborated by the high percentage of variance on each first axis of the PCA (53.2\% for the cranium and $46.7 \%$ for the mandible). Interestingly, such a high phylogenetic component is not obvious in bathyergids, in which the ecological component is stronger, especially regarding the mandible (Gomes Rodrigues et al. 2016). This difference can be observed through the results of our neighbor joining analyses, in which Bathyergus clearly sets apart from all bathyergids, while the phylogenetic position of Bathyergus is nested within bathyergids, close to Georychus (Faulkes et al. 2004; Patterson and Upham 2014; Visser et al. 2019). Bathyergus displays a gracile cranium and an elongated mandible associated with its scratch digging behavior in sandy soils (Fig. 7c; Gomes Rodrigues et al. 2016), while other bathyergids have a short and wide cranium with procumbent incisors to dig in harder soils. Such morphological differences are reinforced by our analyses of disparity with bathyergids being less disparate than spalacids. This major difference in the pattern of 
morphological disparity between spalacids and bathyergids might be the result of their various degree of specialization for digging as well as different evolutionary histories.

\section{Digging abilities vs skull morphology in spalacids and bathyergids}

Previous studies quantified the impact of fossoriality on the skull morphology in bathyergids and also rhizomyines (Gomes Rodrigues et al. 2016; McIntosh and Cox 2016a, 2016b, 2019). In the neighbor joining analysis, the only scratch digging genus, Bathyergus, and chisel-tooth digging bathyergids clearly set apart. This is less obvious for spalacids, because of the putatively important phylogenetic component. Nonetheless, Spalax is clearly differentiated and this genus is often considered as the most adapted rodent to the subterranean life in having vestigial eyes and pinnae (Kingdon et al. 2013). It intensively uses incisors for digging and displays the widest zygomatic arches among spalacids, allowing for large insertions of adductor muscles (Morlok 1983), as well as procumbent shovel-shaped lower incisors used to remove the soil (Fig. 7b; Norris 2017). A similar cranial pattern was also observed and quantified in chisel-tooth digging bathyergids (Fig. 7d; Gomes Rodrigues et al. 2016), even if the latter display procumbent upper incisors.

Such convergent morphological trends are not surprising because Spalax shows biomechanical advantage of the input lever arms for the temporalis similar to that of bathyergids, while the biomechanical estimates for its masseter muscles are very low. However, the explanations for such extreme biomechanical values are slightly different. As chisel-tooth digging bathyergids, Spalax has a mandible with enlarged coronoid processes (Fig. 7b), although less elevated than in other spalacids (Fig. 4). It, however, displays condyles projected posteriorly far from the coronoid processes (Figs. 4 and 7b), which permit it to increase the inlever of the temporalis. This result concurs with the fact that the temporalis, inserted on the coronoid process, represents the main jaw-closing muscle that produces substantial forces at 
the incisors (Hiiemae 1971), and is generally large in chisel-tooth digging rodents (Van Daele et al. 2009; Druzinky 2010; Cox and Faulkes 2014; Cox et al. 2020). The biomechanical advantage of the temporalis might be increased at the expense of the masseters, especially the superficial masseter favoring speed of the mandible rather than output forces observed in chiseltooth digging rodents (Gomes Rodrigues et al. 2016).

The scratch digger Myospalax has less expanded zygomatic arches, reduced insertions for the temporalis, and upright incisors (Fig. 7a). This association of morphological features was also observed in Bathyergus, the only scratch digging bathyergid (Fig. 7c). Their overall morphofunctional characteristics remain, however, very different because Myospalax skull is shorter and more robust than that of Bathyergus (Fig. 7; see Gomes Rodrigues et al. 2016; McIntosh and Cox 2016a), probably in relation to occasional chisel-tooth digging. Subsequent output forces estimated for the temporalis and the superficial masseter also differ significantly between these genera. The study of forearms might provide more information on the scratch digging function and on the potential morphofunctional convergences between Myospalax and Bathyergus (Stein 2000; Lessa et al. 2008). Myospalax also presents enlarged occipital and frontal areas, like Spalax. These enlarged areas are mainly associated with powerful occipital muscles related to the tapping behaviors of spalacines and myospalacines and corresponding to "head drumming or thumping" against the ceiling of their burrows to produce seismic vibration (Rado et al. 1987; Heth et al. 1987; Kingdon et al. 2013; Norris 2017). This mode of communication is frequently used between individuals and represents another adaptation to life underground (Kingdon et al. 2013; Norris, 2017). This behavior is only described in spalacids and was recently observed in Tachyoryctes (Hrouzková et al. 2013,2018), which however does not present these enlarged occipital and frontal areas. Another explanation might be that these traits, coupled with a peculiar shape of the snout in Spalax, and to a lesser extent in Myospalax, could also enable them to perform important head movements. This behavior, absent in 
bathyergids, would allow these spalacids to push the soil up and compact it while digging or to pull it out of the burrows (Hildebrand 1985; Laville et al. 1989; Stein 2000).

Procumbent incisors are highly efficient for chisel-tooth digging. Rhizomyines generally display more procumbent upper incisors than spalacines and myospalacines. Contrary to chisel-tooth digging bathyergids, the root of their upper incisors ends in front of the molars and not behind, which would have permitted them to increase the mechanical efficiency at biting (Landry 1957; McIntosh and Cox 2016b). In addition, they are characterized by lower values of input lever arm for the temporal muscles than Spalax and all bathyergids due to a reduced distance between the condylar and coronoid processes. Nonetheless, they display higher biomechanical advantage for the superficial masseter. Such a combination of morphological and biomechanical characteristics might be explained by the fact that rhizomyines are less subterranean than all other spalacids, and forage extensively aboveground (Norris 2017). However, bamboo rats (Rhizomys and Cannomys) still present wide zygomatic arches and short snout in relation to their chisel-tooth digging activity, which likely implies the presence of massive masticatory muscles (see Morlok 1983), as in most subterranean rodents (e.g., Van Daele et al. 2009; Druzinsky 2010; Cox et al. 2020). Tachyoryctes also forages aboveground, usually in the vicinity of its burrow entrance. It is considered to be less specialized to underground life than other spalacids and African mole-rats in that it builds shorter burrow systems and displays large pinnae to detect predators more efficiently (Jarvis and Sale 1971; Kingdon 1974; Kingdon et al. 2013, Šumbera et al., 2018). Its reduced zygomatic arches could be related to the presence of larger eyes. This configuration potentially constrains the morphology of the masticatory apparatus, precluding the insertion of massive masticatory muscles, as shown in some rodent species (Hautier et al. 2012). In sum, rhizomyines, although less specialized than spalacines, have a global cranial conformation much closer to chisel-tooth bathyergids than to scratch diggers, as previously shown by 
McIntosh and Cox (2016a), once again demonstrating the impact of this mode of digging on the masticatory apparatus of rodents.

\section{Adaptation to fossorial life and evolutionary history of spalacids and bathyergids}

Spalacids, especially Spalax, show some morphological traits convergent with bathyergids. They also display more disparate morphologies associated with less advanced specialization to life underground, which is overall underscored by lower values for estimated biomechanical advantages of the masticatory muscles. As a result, spalacids show an important mosaic of morphological characters, likely related to the independent evolution of fossoriality in each lineage (i.e., spalacines, myospalacines, and rhizomyines). Skull morphologies are less disparate in bathyergids, probably because they adapted to the subterranean life early during their evolutionary history (Fig. 1; Nevo 1979; 1999; Bennett and Faulkes 2000). Morphological adaptations to fossorial life in bathyergids date back to their first appearance in the fossil record, during the early Miocene (Mein and Pickford 2008), while strong adaptations for burrowing in each spalacid subfamilies are not known before the late Miocene, when they started to diversify (Cook 2000; Flynn 2009; López-Antoñanzas et al. 2015; Steppan and Schenk 2017). Moreover, the first known bathyergids already displayed chisel-tooth digging morphologies (e.g., Mein and Pickford 2008; Gomes Rodrigues et al. 2016), whereas the first fossorial spalacids were considered as non-obligate scratch-diggers living more predominantly aboveground (e.g., Sen 1977; Flynn et al. 1985, Flynn 2009; Fig. 1).

Despite the fact the different lineages of bathyergids diverged earlier than the lineages of spalacids, their masticatory apparatus appears quite stable, especially regarding the anatomy of their adductor muscles (Cox et al. 2020). Heterocephalus diverged from other bathyergids between 35 and 23 Ma depending on the phylogenetic analyses (Patterson and Upham 2014; Bryja et al. 2018; Visser et al. 2019), but displays a configuration of masticatory muscles very 
similar to other chisel-tooth digging genera or to the scratch digger Bathyergus. This latter has a masticatory apparatus, although significantly modified, likely inherited from a chisel-tooth digging ancestor (Gomes Rodrigues et al. 2016; Cox et al. 2020). Therefore, an independent acquisition of fossoriality does not constitute the most parsimonious assumption for bathyergids. The case of bathyergids contrasts with the situation observed in spalacines, myospalacines, and rhizomyines that diverged more recently (between 25 and $22 \mathrm{Ma}$; Fig. 1; Steppan and Schenk 2017; He et al. 2020).

A convergent adaptation to fossorial life in spalacids could be more accurately understood by considering the variable shapes of the infraorbital foramina, generally enlarged, and of the zygomatic plate, generally reduced, contrary to most muroids (Figs. 7a and 7b; see Flynn 2009, for more details). Yet, the masticatory apparatus of all bathyergids is derived compared to most Ctenohystrica, in having secondarily reduced infraorbital foramina involving the reduction of the anterior insertion of the infraorbital portion of the zygomaticomandibularis muscle, probably enhancing chisel-tooth digging (Figs. 7c and 7d; Cox and Jeffery 2015; Cox et al. 2020). These morphological characters, generally used for defining the main muscular morphotypes in rodents (Wood 1965), should be quantified and put in relation to adductor muscle insertions and configuration, which remain to be accurately investigated and compared in spalacids. Such studies will enable us to more precisely compare the morphological diversity in spalacids and bathyergids, and to better understand the evolutionary paths taken by each lineage in relation to adaptation to fossorial life.

\section{Data availability}

The datasets generated and analyzed during the current study are available from the corresponding author on reasonable request. 


\section{Compliance with Ethical Standards}

The authors declare that they have no conflict of interest. This article does not contain any studies with human participants or animals performed by any of the authors. Informed consent was obtained from all individual participants included in the study.

\section{Acknowledgments}

We warmly thanks the curators V. Nicolas-Colin, C. Denys (MNHN, Paris), and R. PortelaMiguez (NHM, London) for giving access to the collections of spalacids and bathyergids, respectively. We are grateful to P.-H. Fabre and Q. Martinez (ISEM, Montpellier) for sending us scans of Spalax and Myospalax, and to T. Descamps (MECADEV, MNHN, Paris) for the loan of the microscribe. We thank R. Lebrun (ISEM, Montpellier) who kindly gave us access to Morphotools. We also acknowledge the editor J. Wible, and R. Šumbera (University of South Bohemia, Ceske Budejovice) and P. Cox (Hull York Medical School, University of York) for their fruitful comments and suggestions on the manuscript.

\section{References}

Agrawal VC (1967) Skull adaptations in fossorial rodents. Mammalia 31:300-312

Adams DC, Collyer M, Kaliontzopoulou A (2020) geomorph: Geometric Morphometric Analyses of 2D/3D Landmark Data. Version 3.2.1. R Package

Baverstock H, Jeffery NS, Cobb SN (2013) The morphology of the mouse masticatory musculature. J Anat 223:46-60

Begall S, Burda H, Schleich CE (2007) Subterranean Rodents: News from Underground. Springer, Berlin Heidelberg New York

Bennett NC, Faulkes CG (2000) African Mole-rats: Ecology and Eusociality. Cambridge University Press, Cambridge 
Bookstein FL (1991) Morphometric Tools for Landmark Data Geometry and Biology. Cambridge University Press, Cambridge

Bryja J, Konvičková H, Bryjová A, O. Mikula R, Makundi WN, Chitaukali, Šumbera R (2018) Differentiation underground: range-wide multilocus genetic structure of the silvery mole-rat does not support current taxonomy based on mitochondrial sequences. Mammal Biol 93:82-92. https://doi.org/10.1016/j.mambio.2018.08.006

Burda H (2006) Ear and eye in subterranean mole-rats, Fukomys anselli (Bathyergidae) and Spalax ehrenbergi (Spalacidae): progressive specialisation or regressive degeneration? Animal Biol 56:475-486. https://doi.org/10.1163/157075606778967847

Casanovas-Vilar I, Van Dam J (2013) Conservatism and adaptability during squirrel radiation: what is mandible shape telling us? PLoS One 8:e61298

Conover WJ, Iman RL (1981) Rank transformation as a bridge between parametric and nonparametric statistics. Am Stat 35:124-129

Cook JA, Lessa EP, Hadly EA (2000) Paleontology, phylogenetic patterns, and macroevolutionary processes in subterranean rodents. In: Lacey EA, Patton JL, Cameron GN (eds) Life Underground: The Biology of Subterranean Rodents. University of Chicago Press, Chicago, pp 332-369

Cox PG, Faulkes CG (2014) Digital dissection of the masticatory muscles of the naked molerat, Heterocephalus glaber (Mammalia, Rodentia). PeerJ 2:e448.

Cox PG, Faulkes CG, Bennett NC (2020) Masticatory musculature of the African mole-rats (Rodentia: Bathyergidae). PeerJ 8:e8847. https://doi.org/10.7717/peerj.8847

Cox PG, Jeffery N (2011) Reviewing the morphology of the jaw-closing musculature in squirrels, rats, and guinea pigs with contrast-enhanced microCT. Anat Rec 294:915928

Cox PG, Jeffery N (2015) The muscles of mastication and the function of the medial pterygoid. 
In: Cox PG, Hautier L (eds) Evolution of the Rodents: Advances in Phylogeny, Functional Morphology and Development. Cambridge University Press, Cambridge, pp $350-372$

de Bruijn H, Bosma AA, Wessels W (2015) Are the Rhizomyinae and the Spalacinae closely related? Contradistinctive conclusions between genetics and palaeontology. Palaeobiodivers Palaeoenviron 95:257-269. https://doi.org/10.1007/s12549-015-0195y

Druzinsky RE (2010) Functional anatomy of incisal biting in Aplodontia rufa and sciuromorph rodents. Part 1: masticatory muscles, skull shape and digging. Cells Tissues Organs $191: 510-522$

Fang X et al (2014) Genome-wide adaptive complexes to underground stresses in blind mole rats Spalax. Nature Commun 5:3966

Faulkes CG, Verheyen E, Verheyen W, Jarvis JUM, Bennett NC (2004) Phylogeographical patterns of genetic divergence and speciation in African mole-rats (Family: Bathyergidae). Mol Ecol 13:613-629

Flynn LJ (2009) Chapter 4: The antiquity of Rhizomys and independent acquisition of fossorial traits in subterranean muroids. Bull Am Mus Nat Hist 331:128-156

Flynn LJ, Jacobs LL, Lindsay EH (1985) Problems in muroid phylogeny. Relationship to other rodents and origin of major groups. In: Luckett WP, Hartenberger J-L (eds) Evolutionary Relationships among Rodents. A Multidisciplinary Analysis. Plenum Press. NATO ASI Serie A: Life Sciences, Paris, pp 589-616

Ginot S, Herrel A, Claude J, Hautier L (2019) Morphometric models for estimating bite force in Mus and Rattus: mandible shape and size perform better than lever-arm ratios. J Exp Biol 222:jeb204867. https://doi.org/10.1242/jeb.204867

Gomes Rodrigues H (2015) The great disparity of dental structures and dynamics in rodents: 
new insights into their ecological diversity. In: Cox PG, Hautier L (eds) Evolution of the Rodents: Advances in Phylogeny, Functional Morphology and Development. Cambridge University Press, Cambridge, pp 424-447

Gomes Rodrigues H, Sumbera R, Hautier L (2016) Life in burrows channelled the morphological evolution of the skulls in rodents: the case of African mole-rats (Bathyergidae, Rodentia). J Mammal Evol 23:175-189

Hadid Y, Németh A, Snir S, Pavlíček T, Csorba G, Kázmér M, Major Á, Mezhzherin S, Rusin M, Coşkun Y, Nevo E (2012) Is evolution of blind mole rats determined by climate oscillations? PLoS One 7:e30043. https://doi.org/10.1371/journal.pone.0030043

Hautier L, Lebrun R, Cox PG (2012) Patterns of covariation in the masticatory apparatus of hystricognathous rodents: implications for evolution and diversification. J Morphol 273:1319-1337

Hildebrand M (1985) Digging of quadrupeds. In: Hildebrand M, Bramble DM, Liem KL, Wake DB (eds) Functional Vertebrate Morphology. Harvard University Press, Cambridge, pp 89-109

He Y, Hu S, Ge D, Yang Q, Connor T, Zhou C (2020) Evolutionary history of Spalacidae inferred from fossil occurrences and molecular phylogeny. Mammal Rev 50:11-24. https://doi.org/10.1111/mam.12170

Heth G, Frankenberg E, Raz A, Nevo E (1987) Vibrational communication in subterranean mole rats (Spalax ehrenbergi). Behav Ecol Sociobiol 21:31-33. https://doi.org/10.1007/BF00324432

Hiiemae K (1971) The structure and function of the jaw muscles in the rat (Rattus norvegicus L.) III. The mechanics of the muscles. Zool J Linn Soc 50:111-132

Hrouzková E, Dvořáková V, Jedlička P, Šumbera R (2013) Seismic communication in demon African mole rat Tachyoryctes daemon from Tanzania. J Ethol 31:255-259. 
https://doi.org/10.1007/s10164-013-0374-0

Hrouzková E, Šklíba J, Pleštilová L, Hua L, Meheretu Y, Sillero-Zubiri C, Šumbera R (2018) Seismic communication in spalacids: signals in the giant root-rat and Gansu zokor. Hystrix, Ital J Mammal 29:243-245. https://doi.org/10.4404/hystrix-00118-2018

Jansa SA, Giarla TC, Lim B (2009) The phylogenetic position of the rodent genus Typhlomys and the geographic origin of Muroidea. J Mammal 90:1083-1094

Jansa SA, Weksler M (2004) Phylogeny of muroid rodents: relationships within and among major lineages as determined by IRBP gene sequences. Mol Phyl Evol 31:256-276

Jarvis JUM, Sale JB (1971) Burrowing and burrow patterns of East African mole-rats Tachyoryctes, Heliophobius and Heterocephalus. J Zool 163:451-479. https://doi.org/10.1111/j.1469-7998.1971.tb04544.x

Kim EB, Fang X, Fushan AA, et al (2011) Genome sequencing reveals insights into physiology and longevity of the naked mole rat. Nature 479:223-227

Kingdon J (1974) Mole-rats, blesmols, root-rats. In: East African Mammals, vol II, Pt B (Hares and Rodents), Academic Press. London, pp 474-494

Kingdon J, Happold D, Butynski T, Hoffmann M, Happold M, Kalina J (2013) Mammals of Africa. Volume III: Rodents, Hares and Rabbits. Bloomsbury Publishing, London

Kirby AM, Fairman GD, Pamenter ME (2018) Atypical behavioural, metabolic and thermoregulatory responses to hypoxia in the naked mole rat (Heterocephalus glaber). J Zool 305:106-115. https://doi.org/10.1111/jzo.12542

Kock D, Ingram CM, Frabotta LJ, Honeycutt RL, Burda H (2006) On the nomenclature of Bathyergidae and Fukomys n. gen. (Mammalia: Rodentia). Zootaxa 1142:51-55

Lacey EA, Patton JL, Cameron GN (2000) Life Underground: The Biology of Subterranean Rodents. University of Chicago Press, Chicago

Landry SO Jr (1957) Factors affecting the procumbency of rodent upper incisors. J Mammal 
38:223-234. https://doi.org/10.2307/1376314

Laville E, Casinos A, Gasc J-P, Renous S, Bou J (1989). The mechanism of digging in Arvicola terrestris and Spalax ehrenbergi: functional and evolutional studies. Anat Anzeiger $169: 131-144$

Lebrun R, Ponce de León MS, Tafforeau P, Zollikofer CPE (2010) Deep evolutionary roots of strepsirrhine primate labyrinthine morphology. J anat 216:368-380

Lin G-H, Wang K, Deng X-G, , Nevo E, Zhao F, Su J-P, Guo S-C, Zhang T-Z, Zhao H (2014) Transcriptome sequencing and phylogenomic resolution within Spalacidae (Rodentia). BMC Genomics 15:32

López -Antoñanzas R, Flynn LJ, Knoll F (2013) A comprehensive phylogeny of extinct and extant Rhizomyinae (Rodentia): evidence for multiple intercontinental dispersals. Cladistics 29:247-273

López-Antoñanzas R, Knoll F, Wan S, Flynn LJ (2015) Causal evidence between monsoon and evolution of rhizomyine rodents. Sci Rep 5:9008

Manov I, Hirsh M, Iancu TC, Malik A, Sotnichenko N, Band M, Avivi A, Shams I (2013) Pronounced cancer resistance in a subterranean rodent, the blind mole-rat, Spalax: in vivo and in vitro evidence. BMC Biology 11:91. https://doi.org/10.1186/1741-7007-11$\underline{91}$

McIntosh AF, Cox PG (2016a) The impact of digging on craniodental morphology and integration. J Evol Biol 29:2383-2394. https://doi.org/10.1111/jeb.12962

McIntosh AF, Cox PG (2016b) Functional implications of craniomandibular morphology in African mole-rats (Rodentia: Bathyergidae). Biol J Linnean Soc 117:447-462. https://doi.org/10.1111/bij.12691

McIntosh AF, Cox PG (2019) The impact of digging on the evolution of the rodent mandible. J Morphol 280:176-183. https://doi.org/10.1002/jmor.20929 
Mein P, Pickford M (2008) Early Miocene Rodentia from the northern Sperrgebiet, Namibia. Mem Geol Survey Namibia 20:235-290

Morlok WF (1983). Vergleichend- und funktionell-anatomische Untersuchungen an Kopf, Hals und Vorderextremität subterraner Nagetiere (Mammalia, Rodentia). Schweizerbart Science Publishers, Stuttgart

Musser GG, Carleton MD (2005) Superfamily Muroidea. In: Wilson DE, Reeder DM (eds) Mammal Species of the World. A Taxonomic and Geographic Reference (3rd ed). Johns Hopkins University Press, Baltimore, pp 894-1531

Nevo E (1979) Adaptive convergence and divergence of subterranean mammals. Annu Rev Ecol Evol Syst 10:269-308

Nevo E (1999) Mosaic Evolution of Subterranean Mammals: Regression, Progression and Global Convergence. Oxford University Press, Oxford

Norris RW (2017) Family Spalacidae. In: Wilson DE, Lacher TE, Mittermeier ME (eds) Handbook of the Mammals of the World, Vol 7, Rodents II. Lynx Edicions. Barcelona, pp 08-142

Paradis E, Schliep K (2019) ape 5.0: an environment for modern phylogenetics and evolutionary analyses in R. Bioinformatics, 35:526-528

Patterson BD, Upham NS (2014) A newly recognized family from the Horn of Africa, the Heterocephalidae (Rodentia: Ctenohystrica). Zool J Linnean Soc 172:942-963

Rado R, Levi N, Hauser H, Witcher J, Alder N, Intrator N, Wollberg Z, Terkel J (1987) Seismic signalling as a means of communication in a subterranean mammal. Anim Behav 35:1249-1251. https://doi.org/10.1016/S0003-3472(87)80183-5

Renaud S, Gomes Rodrigues H, Ledevin R, Pisanu B, Chapuis J-L, Hardouin E (2015) Fast evolutionary response of house mice to anthropogenic disturbances on a Sub-Antarctic island. Biol J Linnean Soc 114:513-526 
Rohlf FJ (1999) Shape statistics: Procrustes superimpositions and tangent spaces. J Classif 16:197-223

Sahm A, Bens M, Szafranski K, Holtze S, Groth M, Görlach M, Calkhoven C, Müller C, Schwab M, Kraus J, Kestler HA, Cellerino A, Burda H, Hildebrandt T, Dammann P, Platzer M (2018) Long-lived rodents reveal signatures of positive selection in genes associated with lifespan. PLoS Genetics 14:1-22. https://doi.org/10.1371/journal.pgen.1007272

Sen S (1977) La faune de Rongeurs pliocènes de Çalta (Ankara, Turquie). Bull Mus Natl Hist Nat 465:89-171

Sherman PW, Jarvis JUM (2002) Extraordinary life spans of naked mole-rats (Heterocephalus glaber). J Zool 258:307-311

Stein BR (2000) Morphology of subterranean rodents. In: Lacey EA, Patton JL, Cameron GN (eds) Life Underground: The Biology of Subterranean Rodents. University of Chicago Press, Chicago, pp 19-61

Steppan SJ, Schenk JJ (2017) Muroid rodent phylogenetics: 900-species tree reveals increasing $\begin{array}{llll}\text { diversification } & \text { rates. } & \text { PLoS } & \text { One }\end{array}$ https://doi.org/10.1371/journal.pone.0183070

Šumbera R, Krásová J, Lavrenchenko LA, et al (2018) Ethiopian highlands as a cradle of the African fossorial root-rats (genus Tachyoryctes), the genetic evidence. Mol Phyl Evol 126:105-115. https://doi.org/10.1016/j.ympev.2018.04.003

Van Daele PAAG, Herrel A, Adriaens D (2009) Biting performance in teeth-digging African mole-rats (Fukomys, Bathyergidae, Rodentia). Physiol Biochem Zool 82:40-50

Visser JH, Bennett NC, Jansen van Vuuren B (2019) Phylogeny and biogeography of the African Bathyergidae: a review of patterns and processes. PeerJ 7:e7730. https://doi.org/10.7717/peerj.7730 
Wood AE (1965). Grades and clades among rodents. Evolution 19: 115-130. 
Table 1: List of taxa and material used for geometric morphometric analyses, and associated modes of digging (*additional specimen used for biomechanical estimates).

\begin{tabular}{|c|c|c|c|c|c|}
\hline Suborder & Family & Genus & Cranium & Mandible & Mode of digging \\
\hline \multirow[t]{5}{*}{ Myomorpha } & Spalacidae & Cannomys & 1 & $1(2 *)$ & $\begin{array}{l}\text { Chisel-tooth, } \\
\text { Scratch } \\
\text { Scratch. }\end{array}$ \\
\hline & & Myospalax & 3 & 2 & $\begin{array}{l}\text { Chisel-tooth } \\
\text { (with head) }\end{array}$ \\
\hline & & Rhizomys & 9 & 6 & $\begin{array}{l}\text { Chisel-tooth, } \\
\text { Scratch }\end{array}$ \\
\hline & & Spalax & 14 & 11 & $\begin{array}{l}\text { Chisel-tooth } \\
\text { (with head) }\end{array}$ \\
\hline & & Tachyoryctes & 11 & 4 & Chisel-tooth \\
\hline \multirow[t]{6}{*}{ Ctenohystrica } & Bathyergidae & Bathyergus & 12 & 7 & Scratch \\
\hline & & Fukomys vandewoestijneae & 10 & 5 & Chisel-tooth \\
\hline & & Fukomys mechowii & 10 & 7 & Chisel-tooth \\
\hline & & Georychus & 2 & 3 & Chisel-tooth \\
\hline & & Heliophobius & 14 & 9 & Chisel-tooth \\
\hline & & Heterocephalus & 10 & 10 & Chisel-tooth \\
\hline \multicolumn{2}{|c|}{ Number of specimens } & & 96 & 66 & \\
\hline
\end{tabular}


Fig. 1 Phylogenetic relationships between the investigated spalacid and bathyergid species, including extinct relatives (in grey) and modes of digging. Phylogenetic trees and stratigraphic ranges were based on previous studies using molecular and paleontological data (Cook, 2000; Mein and Pickford, 2008; Patterson and Upham, 2014; Steppan and Schenck, 2017; He et al., 2020).

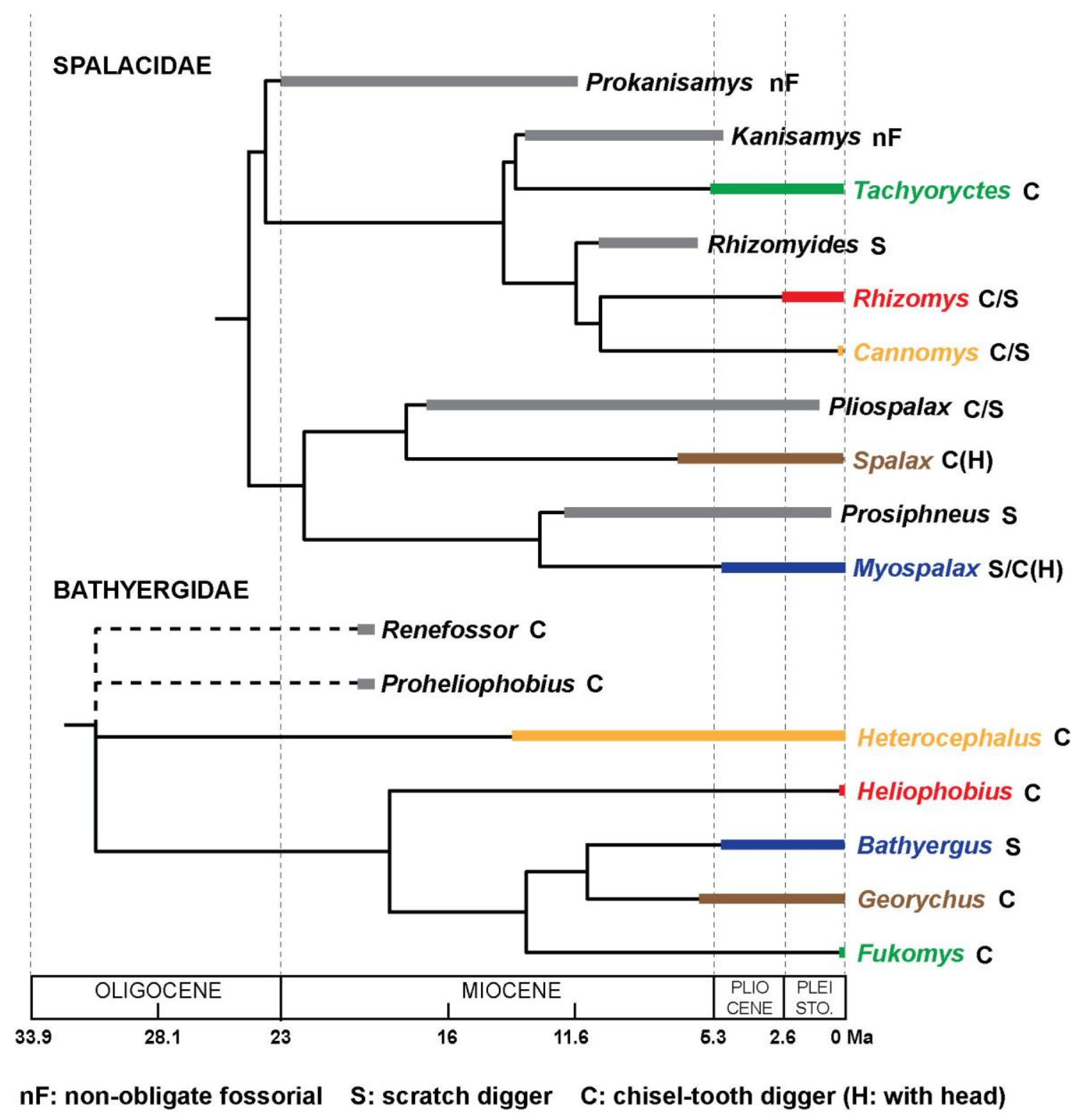


Fig. 2 Landmarks digitized on the cranium (a, dorsal view; c, ventral view; e, lateral view) and the mandible (with the left incisor partly reconstructed; b, lateral view; d, occlusal view) of Spalax sp. (BMNH.10.3.12.10) imaged by using X-ray conventional microtomographic 3D rendering. f, Measure of inlevers (black lines), and outlevers (grey lines) between landmarks digitized on the mandible of Spalax. T: Temporalis, SM: Superficial Masseter, DM: Deep Masseter, I and I2 Incisor (Gomes Rodrigues et al. 2016).
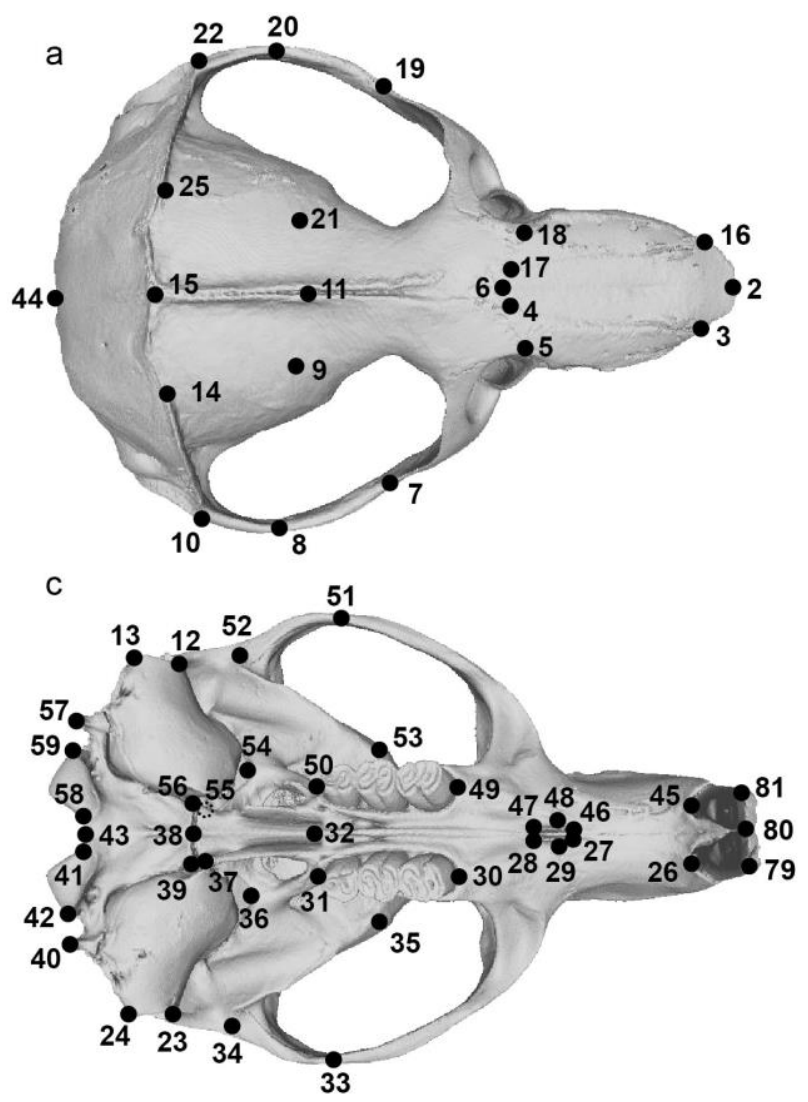

$\mathrm{b}$
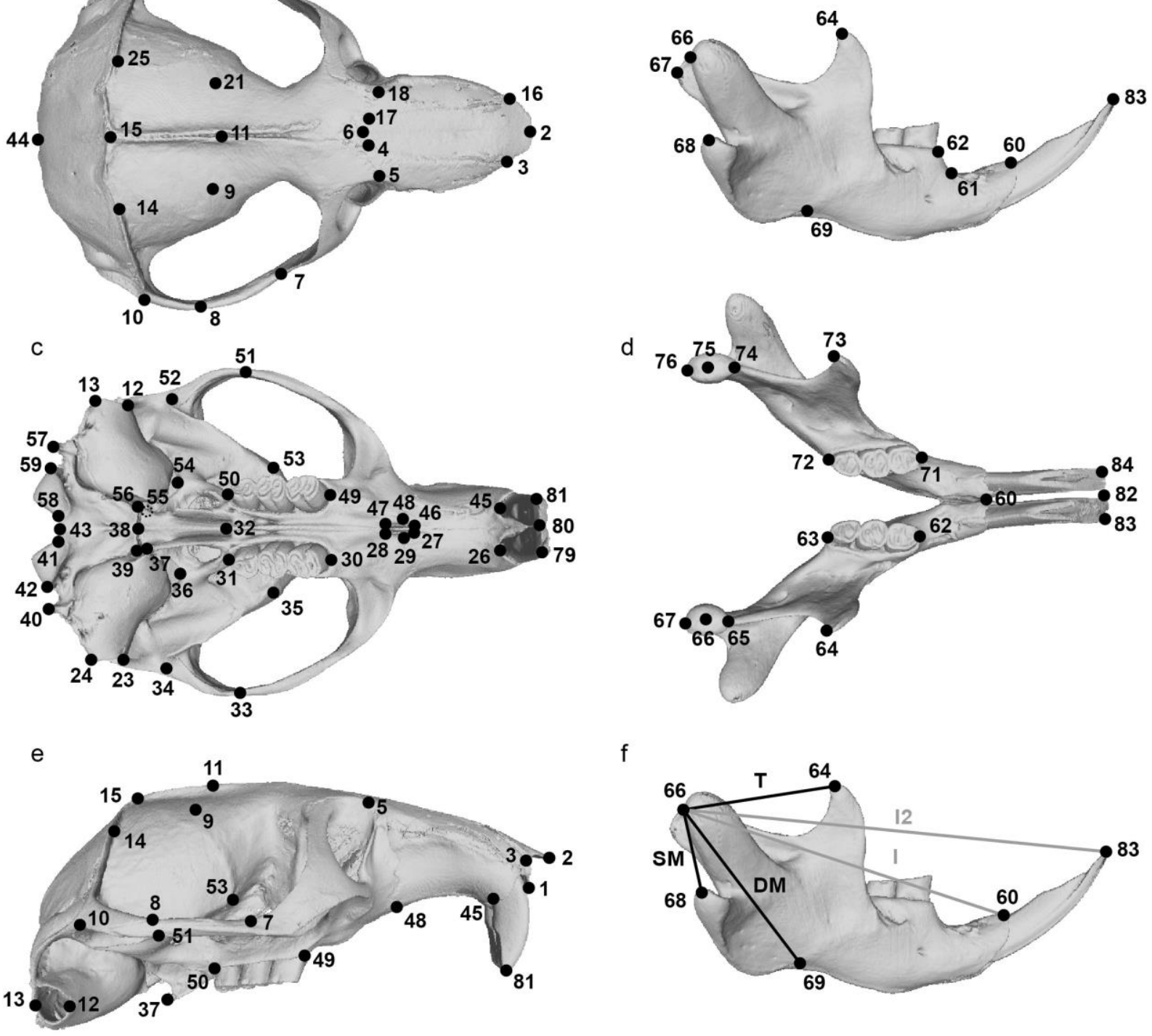

$f$

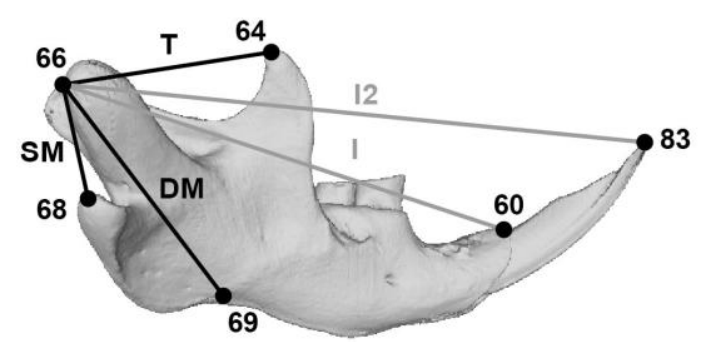


Fig. 3 Principal component analyses realized on crania of Spalacidae and associated virtual deformation on the extreme sides of each axis. Symbols used: $(\diamond)$ Cannomys, ( $¥)$ Myospalax, ( $\square)$ Rhizomys, ( $\Delta)$ Spalax, (×) Tachyoryctes. Yellow and violet code for increases and decreases in surface area, respectively.

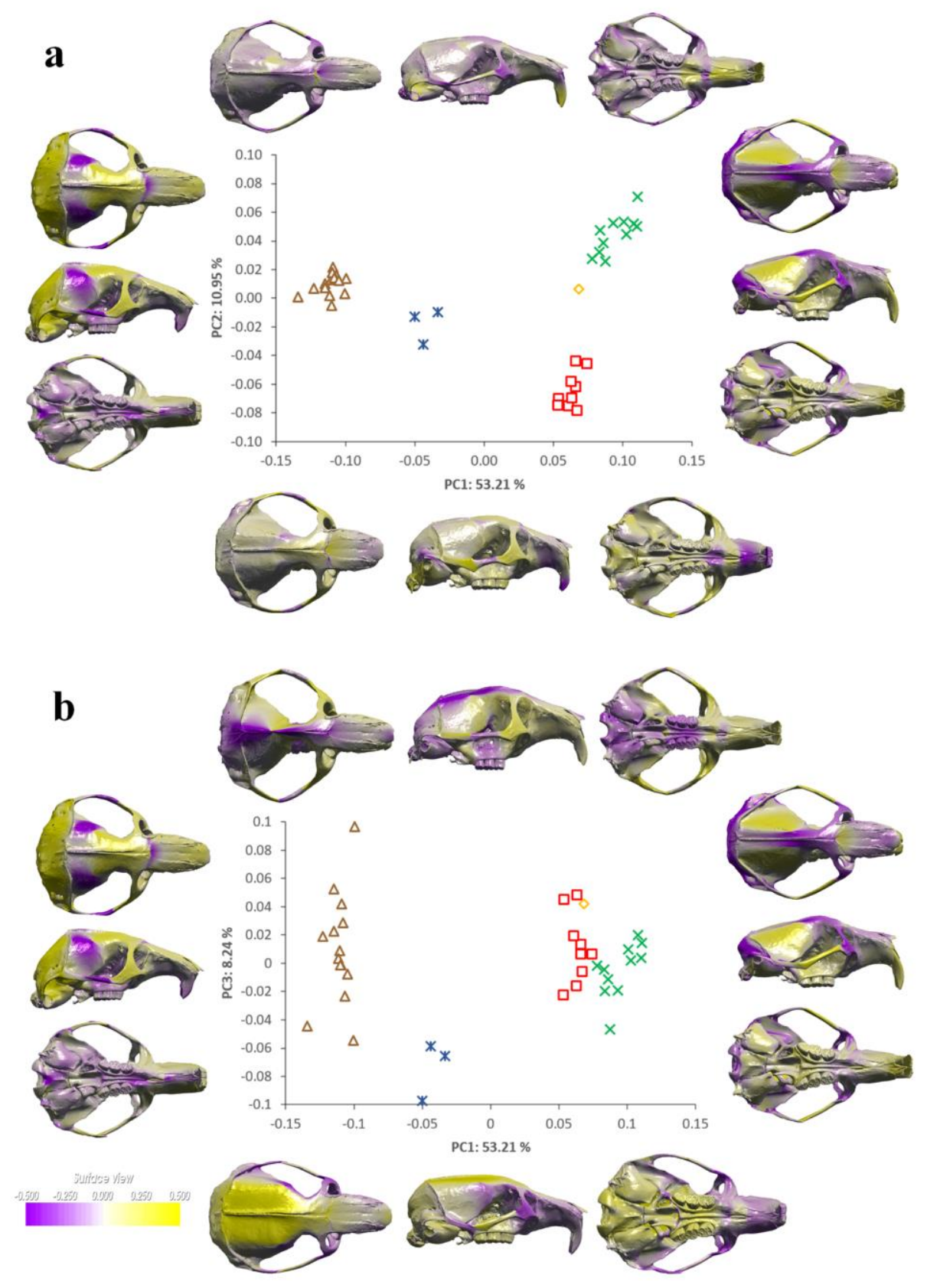


Fig. 4 Principal component analyses realized on mandible of Spalacidae and associated virtual deformation on the extreme sides of each axis. Symbols used: $(\diamond)$ Cannomys, ( $)$ Myospalax, ( $\square)$ Rhizomys, ( $\Delta)$ Spalax, (×) Tachyoryctes. Yellow and violet code for increases and decreases in surface area, respectively.
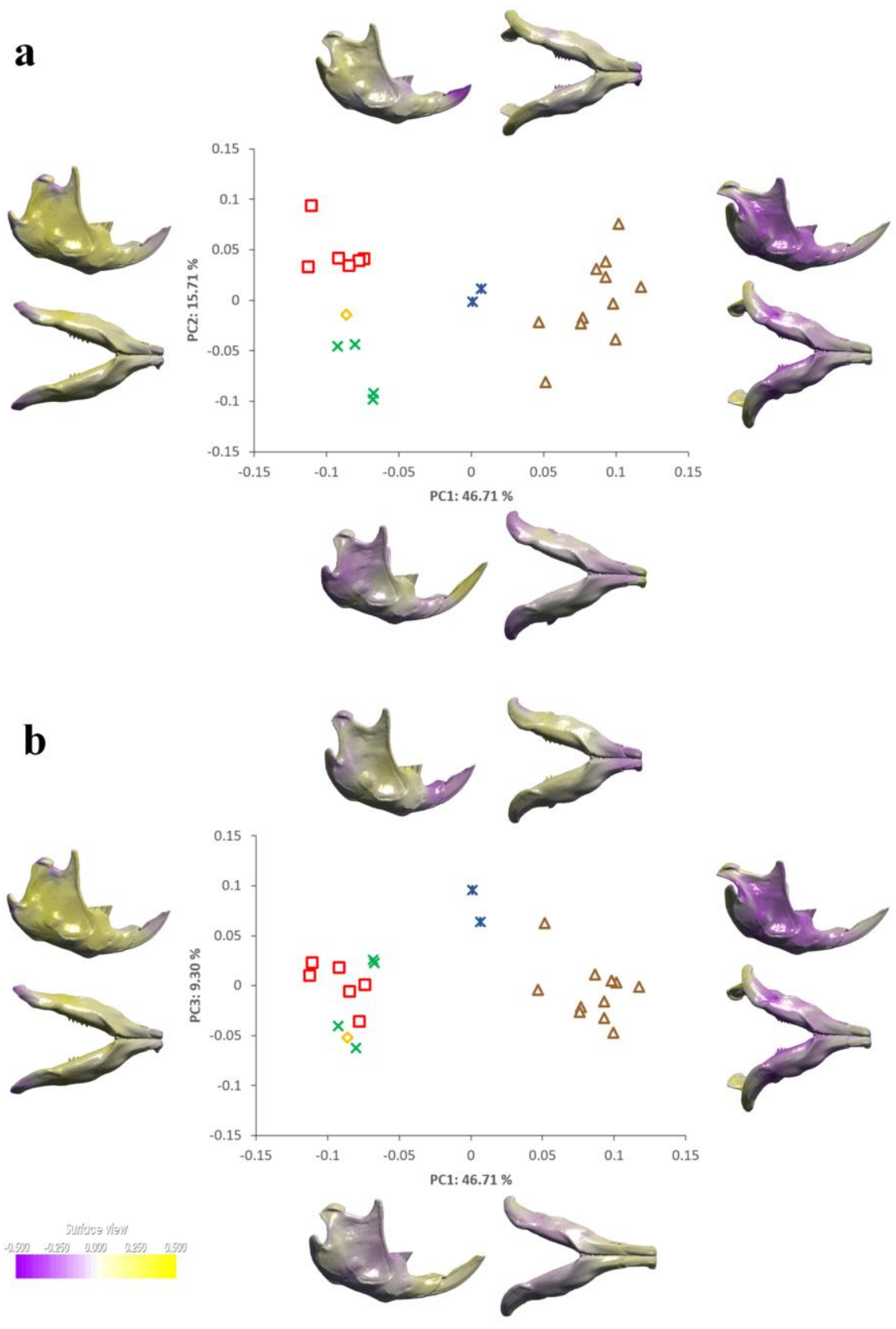
Fig. 5 Trees illustrating morphological distances between Spalacidae and between Bathyergidae resulting from neighbor joining analyses on coordinates data from the PCAs performed on crania and mandibles. Spalacidae - Ca: Cannomys, My: Myospalax, Rh: Rhizomys, Sp: Spalax, Ta: Tachyoryctes. Bathyergidae - Ba: Bathyergus, Fm: Fukomys mech., Fv: Fukomys vand., He: Heliophobius, Ht: Heterocephalus.

\section{Spalacid crania}

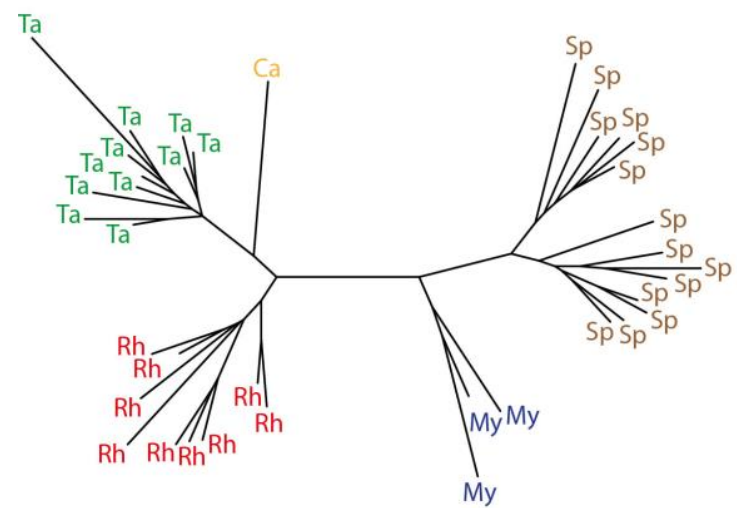

Bathyergid crania

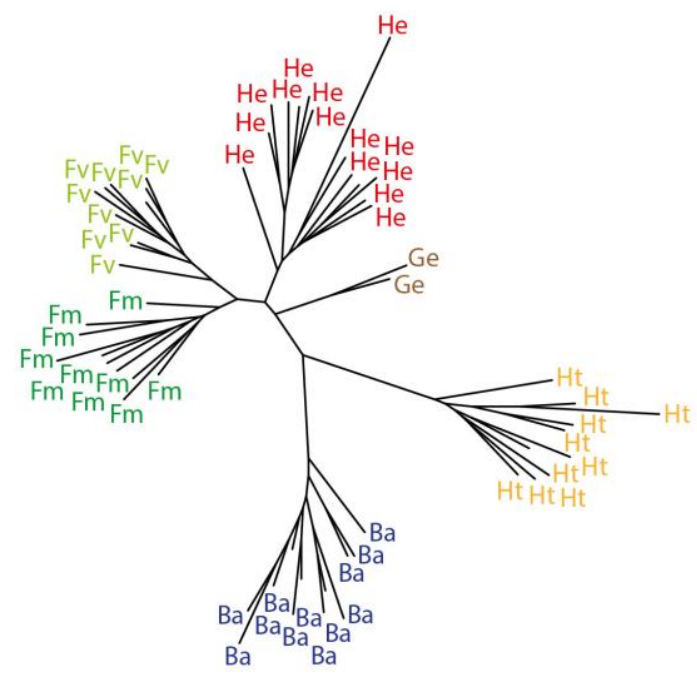

\section{Spalacid mandible}

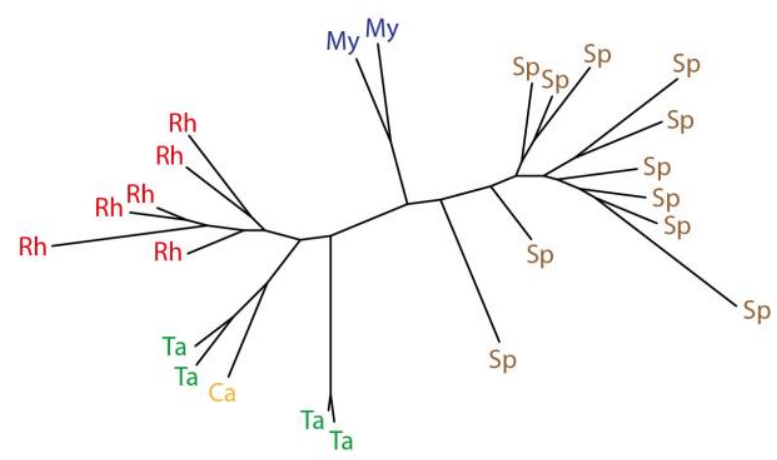

\section{Bathyergid mandible}

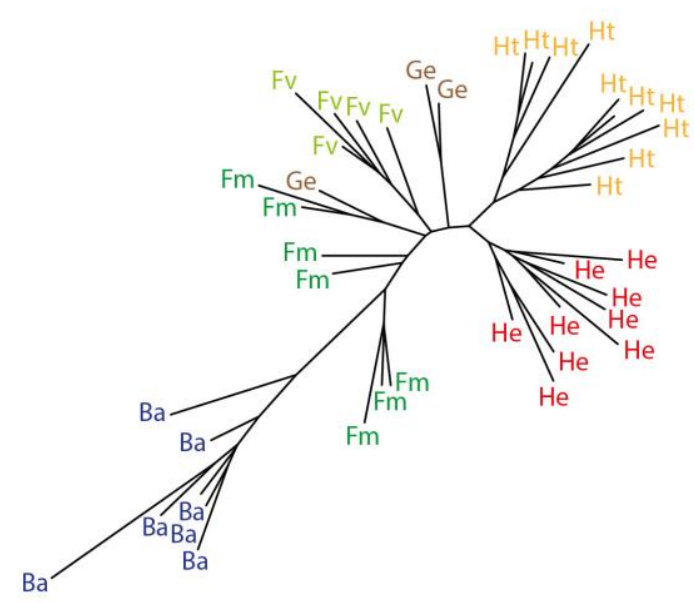


Fig. 6 Graphs representing the mean inlever (muscles)/outlever (incisor) ratio with corresponding standard deviations for spalacids (in black) and bathyergids (in grey).
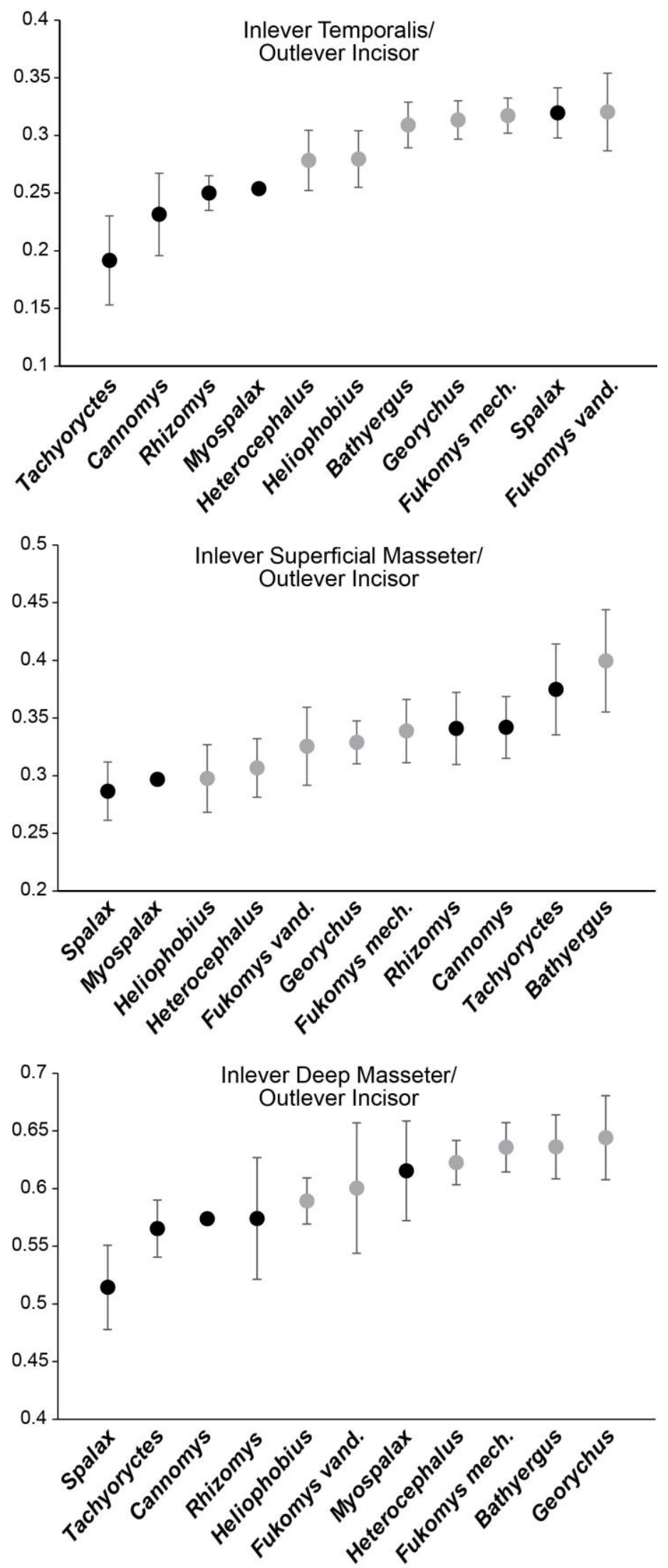
Fig. 7 Skulls of bathyergids and spalacid imaged using X-ray conventional microtomographic 3D renderings with main morphological characters. Dorsal view of crania and lateral views of both crania and mandible of a, Spalax sp. (BMNH.10.3.12.10); b, Myospalax sp. (BMNH.9.1.1.206; with right zygomatic arch partly reconstructed); c, Bathyergus sp. (no number); and d, Heliophobius argenteocinereus (ID13). 
a

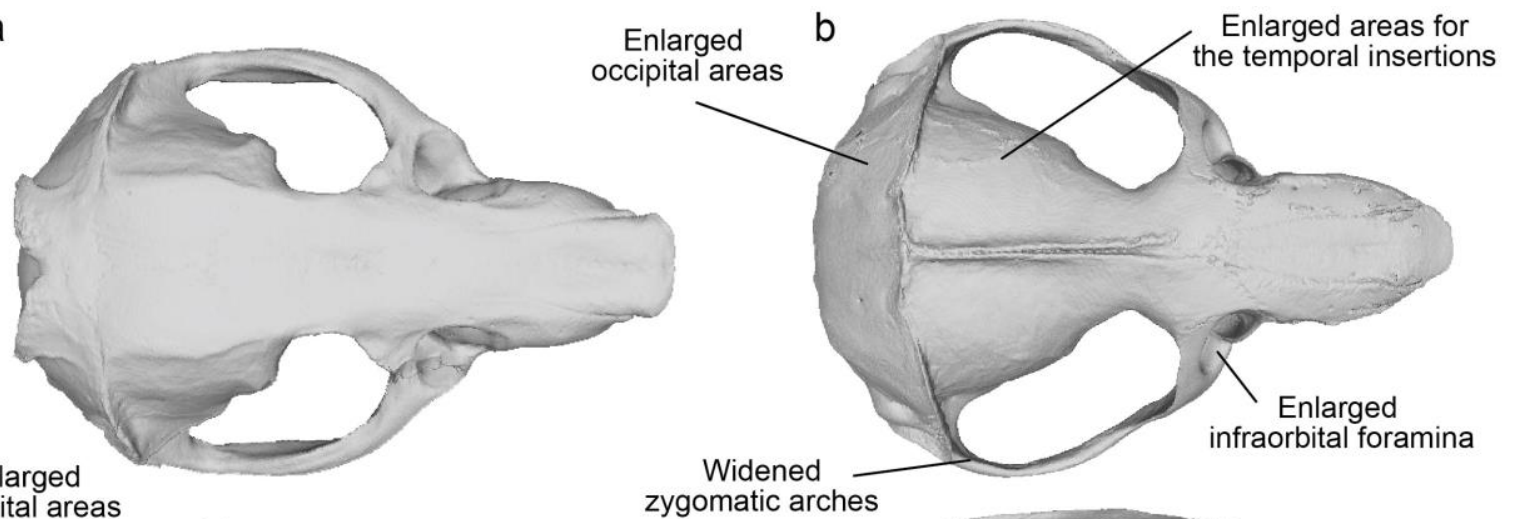

occipital areas

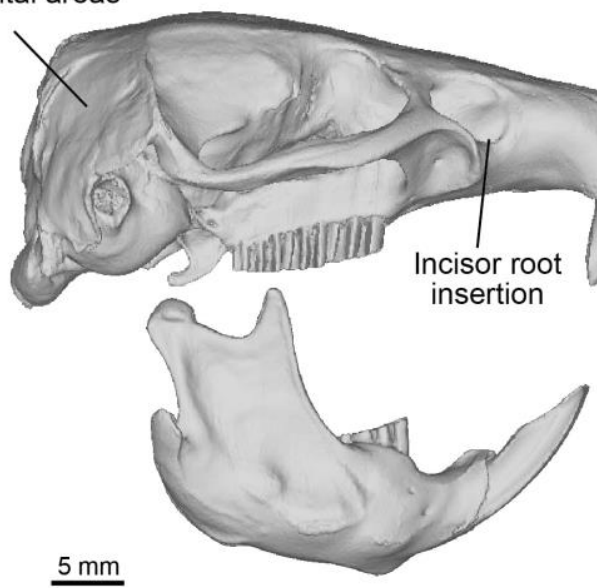

Myospalax

Scratch/Head-lift digger

zygomatic arches

Condyles projected posteriorly

$\underline{5 \mathrm{~mm}}$

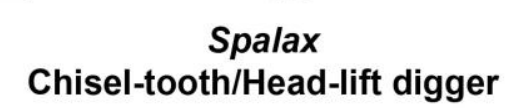

C

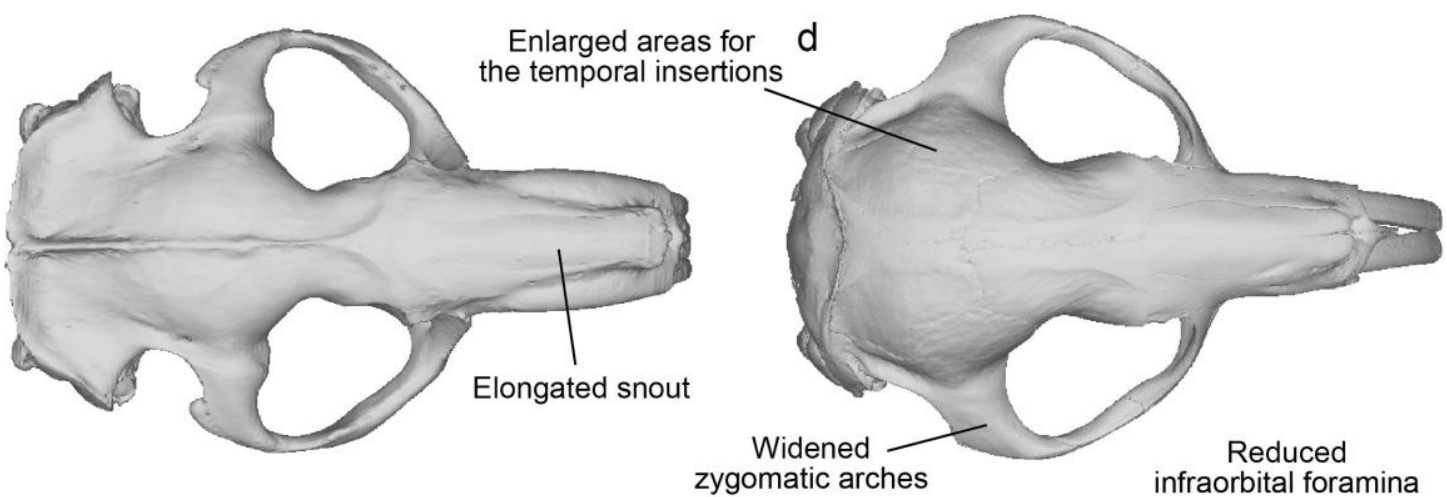

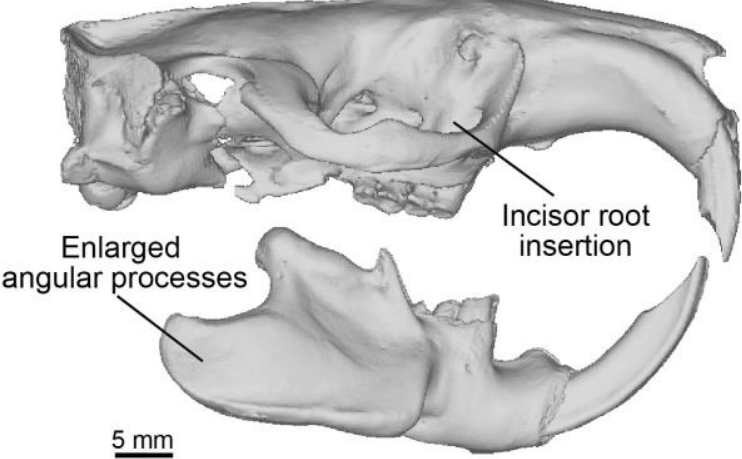

Bathyergus Scratch digger
Heliophobius Chisel-tooth digger 